\title{
Experimental Study on Bending Performance of Composite Sandwich Panel with New Mixed Core
}

\author{
Jing Zhang ${ }^{1}$, Xiamin $\mathrm{Hu}^{1, *}$, Wan Hong ${ }^{1}$, Bing Zhang ${ }^{1}$ and Chengli Zhang ${ }^{1}$ \\ ${ }^{1}$ College of Civil Engineering, Nanjing Tech University, Nanjing 211816, China
}

\begin{abstract}
This paper presents an experimental investigation of bending performance of composite sandwich panels with new mixed core, sandwich panels were tested by four-point bending test. Parametric study was conducted to investigate the influence of different core materials on the failure mode, ultimate bearing capacity, stiffness and ductility of composite sandwich panels. The results of the experimental investigation showed that the mixed core can change the failure mode of sandwich panels. The failure mode of wooden panels is characterized by tensile failure of bottom wood, and the failure mode of composite sandwich panels with wood core is that the surface layer and core are stripped and the webs are damaged by shear, while the failure mode of composite sandwich panels with wood and polyurethane foam mixed core is the shear failure of the web. Composite sandwich panels with GFRP-wood-polyurethane foam core have better bending performance and can effectively reduce the weight of panels.
\end{abstract}

\section{Introduction}

Composite sandwich panel (CSP), composed of two high-strength surface layers with a soft core, and it has been widely used in aerospace, shipping, transportation, civil engineering infrastructure and other fields because of their light weight, high strength, high stiffness, corrosion resistance and fast construction speed [1-2]. The composite action of composite sandwich panel relies heavily on the mechanical behaviour of materials of the surface layer and core, and the composite sandwich panels made of different materials have different combination effects. Therefore, it is necessary to study their bending performance, including stiffness, strength and failure mechanism.

Many researchers have studied the behaviour of different types of composite sandwich panels and various equations for predicting the ultimate bending strength were proposed in the past decades [3-8]. The studies show that light core material is prone to interface peeling and core material shearing. In addition, the traditional core materials have some limitations, such as its own strength, non-uniform performance of heat insulation and sound insulation, high combustion toxicity and low recycling efficiency, which cannot meet the requirements of green environmental protection, limiting the application of sandwich structure in practical engineering [9-13].
In view of the shortcomings of the existing sandwich panels, a new composite sandwich panel with glass fibre reinforced polymer (GFRP) as the surface and web, light wood and polyurethane foam as core materials is proposed. This paper presents the results of four-point bending tests on composite sandwich panel with new mixed core. The varying parameters in the tests were the different core materials. Four different specimens were conducted to obtain the failure modes and load-slip relationships of the specimens. The test results in the present paper could provide a reference to the design and application of composite sandwich panel.

\section{Experimental program}

\subsection{Description of specimens and fabrication}

A total of four composite sandwich panels were designed for the four-point bending tests. The parameters of all the specimens are shown in Table 1, where $l$ is the panel length $(\mathrm{mm}) ; b$ is the panel width $(\mathrm{mm}) ; t$ is the panel thickness $(\mathrm{mm}) ; t_{\mathrm{d}}$ is the wood thickness $(\mathrm{mm}) ; t_{\mathrm{p}}$ is the polyurethane (PU) foam thickness (mm); t $\mathrm{G}$ is the GFRP thickness $(\mathrm{mm})$. Configuration of test specimens is illustrated in Fig. 1.

The interface between the surface layer (GFRP) and the core was formed by vacuum-assisted resin transfer molding (VARTM) process. The upper and lower surfaces of the wood of all specimens were

* Corresponding author: verbundbau@163.com 
slotted with $25 \mathrm{~mm}$ spacing, width of $2 \mathrm{~mm}$ and depth of $2 \mathrm{~mm}$. Fig. 2 shows the fabrication process of specimens.

Table 1. Parameters of specimen.

\begin{tabular}{|c|c|c|c|c|c|c|}
\hline $\begin{array}{c}\text { Specime } \\
\mathrm{n}\end{array}$ & $\begin{array}{c}l \\
(\mathrm{~mm})\end{array}$ & $\begin{array}{c}b \\
(\mathrm{~mm})\end{array}$ & $t(\mathrm{~mm})$ & $t_{\mathrm{d}}(\mathrm{mm})$ & $\begin{array}{c}t_{\mathrm{p}} \\
(\mathrm{mm})\end{array}$ & $\begin{array}{c}t_{\mathrm{G}} \\
(\mathrm{mm})\end{array}$ \\
\hline WPB1 & 1200 & 420 & 72 & 72 & - & - \\
\hline WPB2 & 1200 & 420 & 80 & 72 & - & $4 \times 2$ \\
\hline WPB3 & 1200 & 420 & 80 & $30 \times 2$ & 12 & $4 \times 2$ \\
\hline WPB4 & 1200 & 420 & 80 & - & 72 & $4 \times 2$ \\
\hline
\end{tabular}

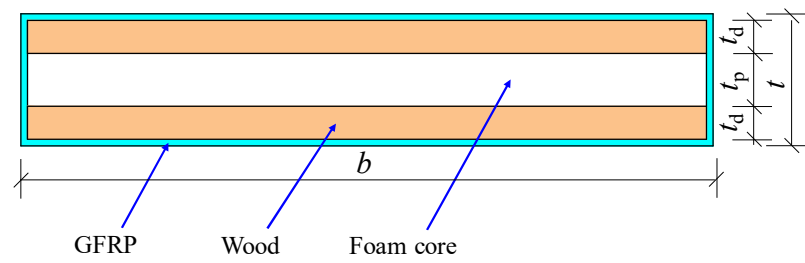

Fig. 1. Cross-sections of CSP specimens.

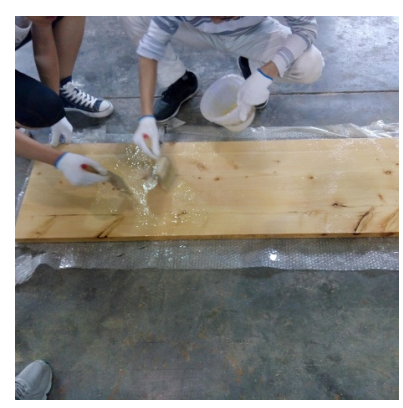

(a) Gluing

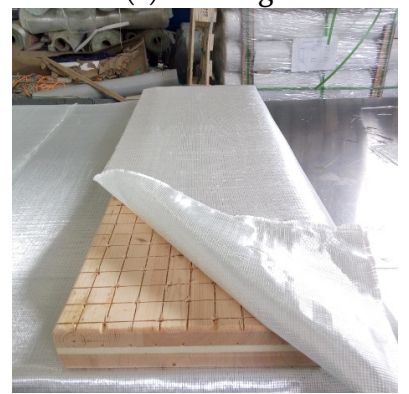

(c) Wrapping GFRP

Fig. 2. Making specimens

\subsection{Material properties}

The wood used in the test was Douglas fir. The density, moisture content and compression modulus parallel to grain of wood was $0.54 \mathrm{~g} / \mathrm{cm}^{3}, 13.84 \%$ and $12455 \mathrm{MPa}$, respectively. The mechanical properties of GFRP, wood and polyurethane foam are summarized in Tables 2 and Table 3, where $f$ is the tensile strength (MPa), $E_{t}$ is the tensile modulus (MPa), $f_{s}$ is the shear strength $(\mathrm{MPa}), E_{\mathrm{s}}$ is the shear modulus $(\mathrm{MPa}), f_{\mathrm{c}}$ is the compressive strength $(\mathrm{MPa}), E_{\mathrm{c}}$ is the compressive modulus ( $\mathrm{MPa})$.

Table 2. Mechanical properties of GFRP and PU.

\begin{tabular}{|c|c|c|c|c|c|c|}
\hline Type & $\begin{array}{c}f_{\mathrm{t}} \\
(\mathrm{MPa})\end{array}$ & $\begin{array}{c}E_{\mathrm{t}} \\
(\mathrm{MPa})\end{array}$ & $\begin{array}{c}f_{\mathrm{s}} \\
(\mathrm{MPa})\end{array}$ & $\begin{array}{c}E_{\mathrm{s}} \\
(\mathrm{MPa})\end{array}$ & $\begin{array}{c}f_{\mathrm{c}} \\
(\mathrm{MPa})\end{array}$ & $\begin{array}{c}E_{\mathrm{c}} \\
(\mathrm{MPa})\end{array}$ \\
\hline GFRP & 322.9 & 21820 & 8.45 & 3120 & 15.50 & 20530 \\
\hline PU & 0.72 & 34080 & 0.44 & 16220 & 1.22 & 35420 \\
\hline
\end{tabular}

Table 3. Mechanical properties of Douglas fir.

\begin{tabular}{|c|c|c|c|c|}
\hline \multirow{2}{*}{$\begin{array}{c}\text { Parallel to } \\
\text { the grain }\end{array}$} & Tensile & $\begin{array}{c}\text { Compressiv } \\
\text { e }\end{array}$ & \multicolumn{2}{|c|}{ Shear } \\
\cline { 4 - 5 } & & Radial & $\begin{array}{c}\text { Tangentia } \\
\text { l }\end{array}$ \\
\hline $\begin{array}{c}\text { Strength } \\
(\mathrm{MPa})\end{array}$ & 90.84 & 41.48 & 10.15 & 8.61 \\
\hline
\end{tabular}

\subsection{Test setup and instrumentation}

Four-point bending test was carried out on the specimens WPB1-WPB4. The MTS test machine with a range of $200 \mathrm{kN}$ was used for loading, and the loading rate was $2 \mathrm{~mm} / \mathrm{min}$. The loading system was in accordance with ASTM C393 [14]. Three LVDTs are used to measure the vertical displacement at the support and the middle of the span. The test set-up and LVDT layout of specimens were shown in Fig. 3.

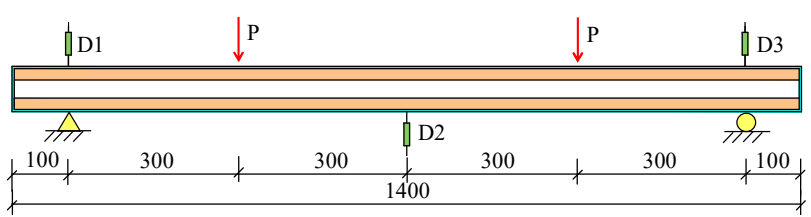

Fig. 3 Test set-up and LVDT layout of specimens (unit: $\mathrm{mm}$ ).

\section{Test results and discussion}

\subsection{Failure modes}

For specimen WPB1, when the load was about 60 $\mathrm{kN}$, oblique crack appeared at the loading point along the grain direction of the wood. When the load increased to $85 \mathrm{kN}$, tensile failure was observed at the bottom of the specimen, and the crack continued to expand upward along the grain direction and stops at the interface of two layers of wood, as shown in Fig. 4.

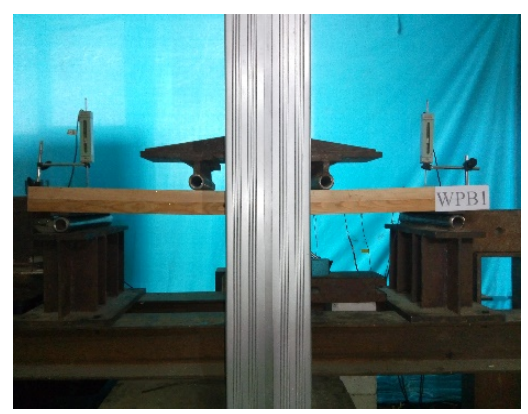

(a) Specimen WPB1 before test 


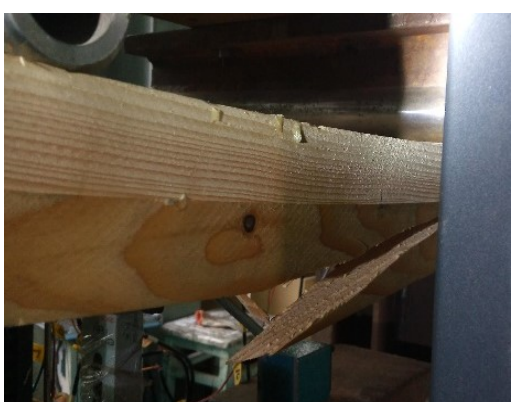

(b) Tensile failure of wood

Fig. 4 Failure modes of specimen WPB1.

For specimen WPB2, when the load reached $98 \mathrm{kN}$, the load fell to $83 \mathrm{kN}$ and the deflection increased rapidly. Moreover, the peeling of GFRP surface layer and wood core was observed. When the load dropped to $73 \mathrm{kN}$, the GFRP was cut at the end of the panel, as shown in Fig. 5.

For specimen WPB3 and WPB4, it can be observed that an identical failure mode was the shear failure of the webs, as shown in Fig. 6(a) and Fig. 6(b).

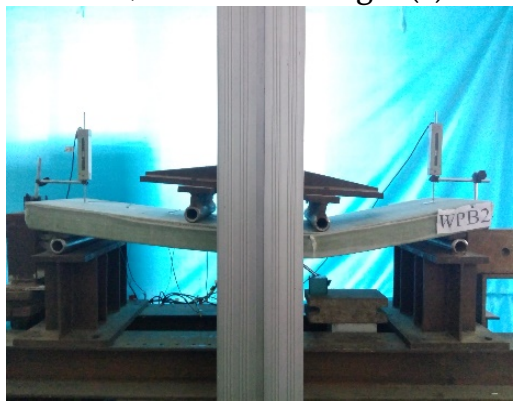

(a) Shear failure of the webs

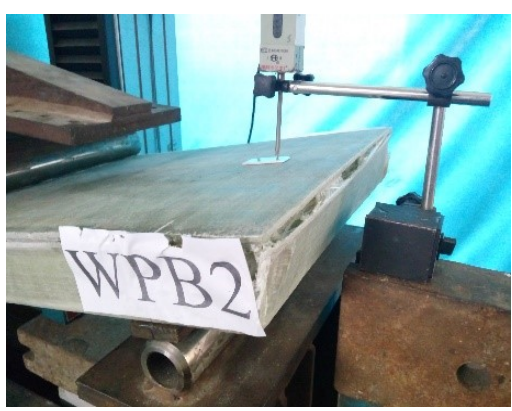

(b) Interface peeling

Fig. 5 Failure modes of specimen WPB2.

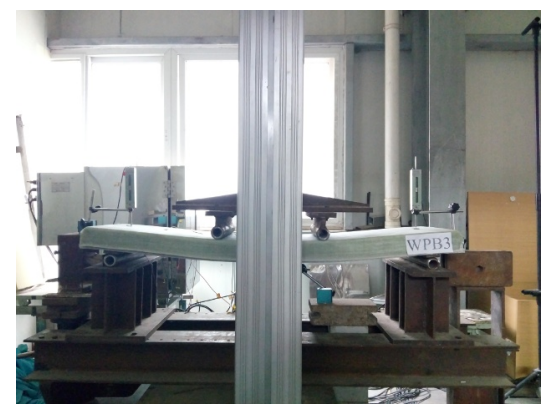

(a) Deformation in the specimen WPB3

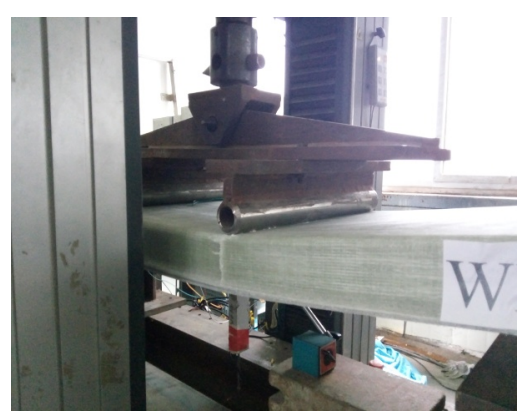

(b) Failure mode of specimen WPB3

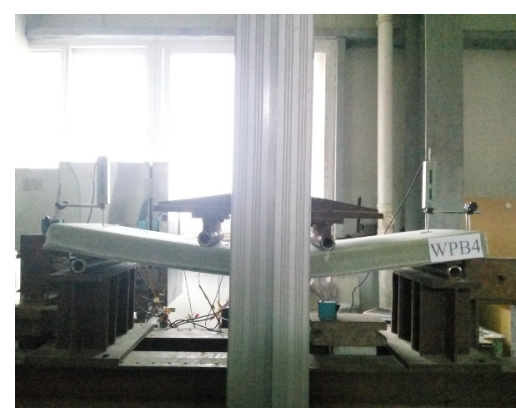

(c) Deformation in the specimen WPB4

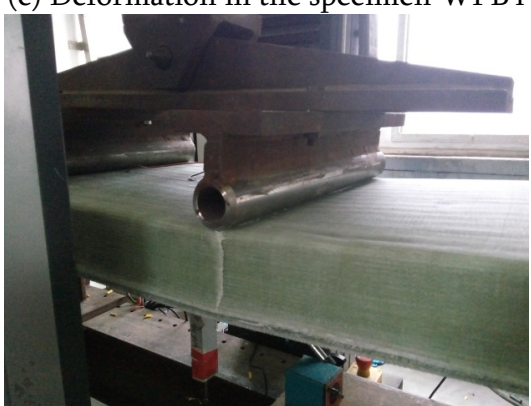

(d) Failure mode of specimen WPB4

Fig. 6 Failure modes of specimen WPB3 and WPB4

\subsection{Load-deflection curves}

Figure 7 shows the curves of mid-span deflection against load for the four specimens. It can be seen that the load-deflection curves of four specimens exhibited similar linear relationship at the initial stage of loading. After reaching the peak load, different specimens showed different characteristics. Although wood tensile failure occurred in specimen WPB1, the load almost did not decrease due to good plasticity of wood. while the other three specimens dropped suddenly after reaching the peak load. The main reason is the shear failure of GFRP surface layer under complex stress, resulting in a significant drop in load. Subsequently, the curves showed distinct peaks, and the corresponding load values are less than the first peak load values except specimen WPB3. Overall, the composite sandwich panels exhibited good ductility.

Comparing the failure modes of all specimens, it can also be concluded that the mixed core materials can change the stress distribution in the panel, thus changing the failure mode of the panel, and improving the stiffness and bearing capacity of the panel. 


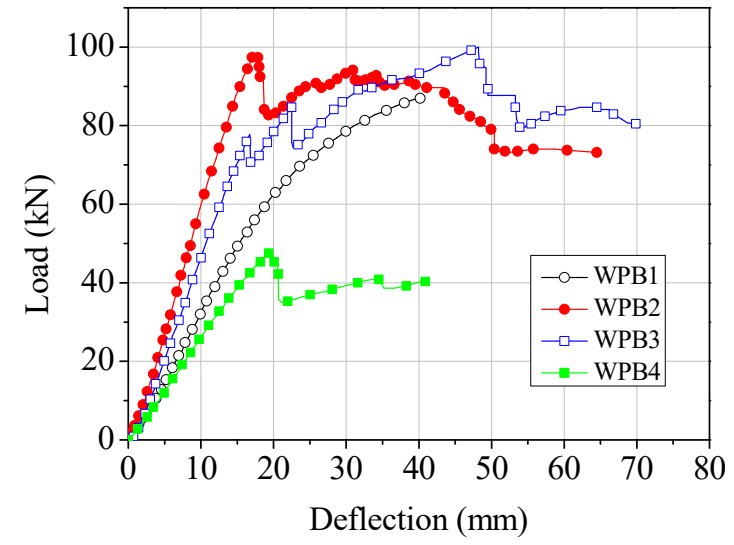

Fig. 7 Load-deflection curves

A summary of test results is given in Table 4, where $W$ is total weight of specimen $(\mathrm{kg}), P_{\mathrm{m}}$ is the ultimate bearing capacity $(\mathrm{kN}), f_{\mathrm{m}}$ is the mid-span deflection at $P_{\mathrm{m}}, f_{\mathrm{u}}$ is ultimate deflection (mm), $K$ is the initial stiffness defined as the ratio of the first peak load to the corresponding deflection in the load-deflection curve $(\mathrm{kN} / \mathrm{mm}), \mu$ is the displacement ductility factor defined as the ratio of the deflection corresponding to the first peak load to $f_{u}$.

Table 4. Summary of test results.

\begin{tabular}{|c|c|c|c|c|c|c|}
\hline Specimen & $\begin{array}{c}W \\
(\mathrm{~kg})\end{array}$ & $\begin{array}{c}P_{\mathrm{m}} \\
(\mathrm{kN})\end{array}$ & $\begin{array}{c}f_{\mathrm{m}} \\
(\mathrm{mm})\end{array}$ & $\begin{array}{c}f_{\mathrm{u}} \\
(\mathrm{mm})\end{array}$ & $\begin{array}{c}K \\
(\mathrm{kN} / \mathrm{mm})\end{array}$ & $\mu$ \\
\hline WPB1 & 34.6 & 86.94 & 40.17 & 40.17 & 2.16 & 1 \\
\hline WPB2 & 34.6 & 97.95 & 17.21 & 64.48 & 5.69 & 3.75 \\
\hline WPB3 & 32.1 & 100.0 & 48.22 & 69.85 & 4.65 & 4.18 \\
\hline WPB4 & 18.3 & 47.50 & 19.35 & 40.89 & 2.46 & 2.11 \\
\hline
\end{tabular}

To investigate the influence of GFRP surface layer and different core materials on the bending performance of the composite sandwich panel, the test results for each specimen were compared.

It can be seen from Fig. 7 and Table 4 that the ultimate bearing capacity, initial stiffness and displacement ductility factor of the specimen WPB2 was $12.7 \%, 163.4 \%$ and $275.0 \%$ higher than the specimen WPB1, respectively. It can be concluded that the ultimate bearing capacity, initial stiffness and ductility of wood panel can be effectively improved by using GFRP surface layer.

Compared with the specimen WPB2, the ultimate bearing capacity of specimen WPB3 is slightly higher than that of specimen WPB2, and its ductility is obviously better than the specimen WPB2, but the initial stiffness of specimen WPB2 is larger. It can be indicated that the failure modes of composite sandwich panels can be changed by using wood and polyurethane foam as the mixed core to avoid surface layer and core material peeling, and the ductility of composite sandwich panels can be improved and the total weight can be reduced.

From Fig. 7 and Table 4, it can be indicated that the bending performance of composite sandwich panels are related to core materials, and the bending performance of sandwich panels with wood core is significantly better than that of composite sandwich panels with polyurethane foam core, but the bending performance of sandwich panels with mixed core (wood and polyurethane foam) is better than that of composite sandwich panels with wood core, Compared with the specimen WPB4, the ultimate bearing capacity of specimen WPB2 and WPB3 increased by $106.2 \%$ and $110.5 \%$, respectively. And the initial stiffness of specimen WPB2 and WPB3 increased by $131.3 \%$ and $89.0 \%$, respectively. In addition, the displacement ductility factor of specimen WPB2 and WPB3 increased by $77.7 \%$ and $98.1 \%$, respectively.

Therefore, the composite sandwich panels with GFRP as the surface and web, wood and polyurethane foam as core material have better bending performance and can effectively reduce weight.

\section{Conclusions}

This paper presented the results of the four composite sandwich panels. The influence of GFRP surface layer and different core materials on the bending performance of the composite sandwich panel on the failure modes, ultimate bearing capacity, initial stiffness and displacement ductility factor of composite sandwich panels are investigated. The following conclusions can be drawn:

The test results of the experimental investigation indicated that the mixed core can change the failure mode of sandwich panels. The failure mode of specimen WPB1 is characterized by brittle failure of wood, and the failure mode of specimen WPB2 is the surface layer and core material peeling, while the failure modes of specimens WPB3 and WPB4 are the shear failure of the webs, showing good ductility. Moreover, the ultimate bearing capacity, initial stiffness and ductility of wood panel can be effectively improved by using GFRP surface layer, and the bending performance of the composite sandwich panel with GFRP as the surface and web, wood and polyurethane foam as mixed core materials is obviously better than these of wood panel, composite sandwich panel with wood core and composite sandwich panel with polyurethane foam core.

Overall, the composite sandwich panels with GFRP as the surface and web, wood and polyurethane 
foam as core materials have the advantages of light weight and better bending performance, and it can effectively avoid the failure mode of surface layer and core material peeling in practical engineering.

\section{Acknowledgements}

This study is supported by the National Natural Science Foundation of China (Grant No. 51478220), Jiangsu Provincial Department of Water Resources Science and Technology Project "Standardized design and research of small irrigation and drainage pumping stations in rural areas of Jiangsu province" (Grant No. 2013008) and Jiangsu Provincial Department of Education (No. 16KJB560005). These supports are gratefully acknowledged. Thanks are also owed to the Structures Laboratory of the Civil Engineering Department of the Nanjing Tech University, personnel where the tests were conducted.

\section{References}

1. Belouettar S, Abbadi A, Azari Z, Belouettar R, Freres P. Experimental investigation of static and fatigue behaviour of composites honeycomb materials using four point bending tests, Compos. Struct. 87(09) (2008) 265-273.

2. Russo A, Zuccarello B. Experimental and numerical evaluation of the mechanical behaviour of GFRP sandwich panels, Compos. Struct. 81(04) (2007) 575-86.

3. Steeves C A, Fleck N A. Collapse mechanisms of sandwich beams with composite faces and a foam core, loaded in three-point bending. Part I: analytical models and minimum weight design, Int. J. Mech. Sci. 46(04) (2004) 585-608.

4. Hai F, Weiqing L, Li W. Mechanical Properties and Manufacturing Process of Grooved Perforation Sandwich Composites, J. Build. Mater. 4 (2008): 495-499.

5. Fubin Z, Weiqing L, Lu W, Yujun Q, Ding Z, Hai F. Flexural behavior of hybrid composite beams with a bamboo layer and lattice ribs, J. Reinf. Plast. Comp. 34(07) (2015): 521-533.

6. F. Meraghni, F. Desrumaux, M.L. Benzeggagh. Mechanical behaviour of cellular core for structural sandwich panels, Compos. Part A : Appl. Sci. Manufac. 30(06) (1999) 247-253.

7. A.G. Mamalis, K.N. Spentzas, N.G. Pantelelis, D.E. Manolakos, M.B. Ioannidis. A new hybrid concept for sandwich structures, Compos. Struct. 83(04) (2008) 335-340

8. Umer R, Waggy EM, Haq M. Experimental and numerical characterizations of flexural behavior of VARTM-infused composite sandwich structures, J. Reinf. Plast. Compos. 31 (2012) 67-76.
9. Romanoff F, Varsta P. Bending response of webcore sandwich beams, Compos. Struct. 73(04) (2006) 478-487.

10. Thomas K, Jan R, Julia de C. GFRP-balsa sandwich bridge deck: concept, design and experimental validation, J. Compos. Constr. 7 (2013) 3-21.

11. Rizov V, Shipsha A, Zenkert D. Indentation study of foam core sandwich composite panels, Compos. Struct. 69(01) (2005) 95-102.

12. Borsellino C, Calabrese L, Valenza A. Experimental and numerical evaluation of sandwich composite structures, Compos. Sci. Technol. 64(10-11) (2004) 1709-1715.

13. Pitarresi G, Carruthers JJ, Robinson AM, Torre G, Kenny JM, Ingleton S. A comparative evaluation of crashworthy composite sandwich structures, Compos. Struct. 78(01) (2007) 34-44.

14. ASTM C393. Standard test method for flexural properties of sandwich constructions, 2000 . 